\title{
Cigarette smoking in British men and selection for coronary artery bypass surgery
}

Richard W Morris, Alison K McCallum, Mary Walker, Peter H Whincup, Shah Ebrahim, A Gerald Shaper

\begin{abstract}
Objective-To examine the relation between smoking status, clinical need, and likelihood of coronary artery bypass grafting in middle aged men.

Design-A prospective study of cardiovascular disease in British men aged 40 to 59 years, screened in 1978-80 and followed until December 1991.

Subjects and setting-7735 men drawn from one general practice in each of 24 British towns.

Main outcome measure-Coronary artery bypass graft surgery.

Results-Of the 3185 current smokers, 38 $(1 \cdot 03 / 1000 /$ year) underwent coronary artery bypass surgery compared with 47 of $2715(1.45 / 1000 /$ year $)$ ex-smokers, and 19 of $1817(0 \cdot 85 / 1000 /$ year $)$ never-smokers. Ex-smokers had a lower incidence of major ischaemic heart disease during follow up than current smokers. After adjustment for incidence of ischaemic heart disease during follow up, the hazard ratio of coronary artery bypass surgery for ex-smokers compared with smokers was 1.52 (95\% confidence interval 0.99 to 2.34). Ex-smokers were more likely at screening to recall a doctor diagnosis of ischaemic heart disease than smokers $(7 \cdot 1 \%$ v $5 \cdot 3 \%)$, but among those who recalled a doctor diagnosis, smokers were less likely to undergo coronary artery bypass surgery than ex-smokers $(9 \cdot 4 \% v$ $3 \cdot 5 \%, P=0 \cdot 026)$. By 1992 , men defined as smokers at screening were no less likely than ex-smokers to have been referred to a cardiologist $(18 \cdot 5 \% \quad v \quad 18 \cdot 8 \%$, nor to report having undergone coronary angiography less frequently than exsmokers $(12 \cdot 7 \% v 11 \cdot 4 \%)$.
\end{abstract}

Conclusion-Even allowing for the strong relation between coronary artery bypass surgery and clinical need, continuing smokers were less likely to undergo coronary artery bypass surgery than ex-smokers. A complex interplay exists between the men's experience of heart disease, the decision to stop smoking, and the willingness of doctors to consider coronary artery bypass surgery.

(Heart 1996;75:557-562)

Keywords: coronary artery bypass surgery; smoking status; patient selection; ischaemic heart disease
Ischaemic heart disease is an important avoidable cause of morbidity and mortality in Britain, and targets for reduction have been set by the Government. ${ }^{1}$ Manipulation of personal risk factors, in particular reduction of cigarette smoking and change in diet, has been emphasised. However, treatment of those with established disease is also important, and coronary artery bypass surgery has been shown to be an effective intervention. ${ }^{2}$ Ideally treatment should be based solely on clinical need, but studies using data from electoral wards showed that rates of cardiac catheterisation were lower in women ${ }^{3}$ and in socially deprived groups, ${ }^{45}$ even when hospital admission rates for ischaemic heart disease were taken into account. The availability of cardiac surgery services in the private sector may be an important factor. ${ }^{6}$ American studies have shown differences in rates of cardiological procedures with regard to ethnicity, with African-Caribbeans being particularly disadvantaged. ${ }^{78}$

Only one of the cited studies has been able to examine the relation between coronary artery bypass surgery and clinical need in individuals, ${ }^{7}$ and even that study (based on men with cardiovascular disease discharged from hospital) did not consider the possible role of cigarette smoking. This is particularly important since selection of patients for coronary artery bypass surgery by some surgeons is influenced by patients' smoking habits, ${ }^{9-11}$ and smoking is more common among those of manual social class. ${ }^{12}$

We have examined the influence of age, social class, region of residence, and smoking status on the likelihood of undergoing coronary artery bypass surgery in a populationbased national study of cardiovascular disease in middle aged men.

\section{Patients and methods}

The British Regional Heart Study (BRHS) is a national prospective study of the aetiology and regional variation of ischaemic heart disease. Information was gathered by questionnaire and by clinical and biochemical measurement when men were recruited and examined between 1978 and 1980. A total of 7735 men aged 40 to 59 were selected from one general practice in each of 24 British towns. The towns were selected to represent the range of mortality from cardiovascular disease. ${ }^{13}$ The population of the towns ranged from 50000 to 100000 (1971 Census) and none presently contains a specialised cardiological tertiary 
referral centre. Men were randomly selected for screening from the practice age-sex register. A questionnaire (Q1) was administered to the men by a research nurse, and included details on ischaemic heart disease, respiratory disease, cause of parental death, smoking habits, and social class. Physical measurements included blood pressure and forced expiratory volume. Blood samples were taken for biochemical estimations, including serum total cholesterol.

At the fifth anniversary of screening for men in the various towns, a questionnaire (Q5) was mailed to the survivors. This included similar questions on ischaemic heart disease and smoking habits. A further questionnaire (Q92) was sent to all men in November 1992, in order to ascertain current perceived levels of health, changes in cardiovascular risk factors, investigation and treatment for ischaemic heart disease, and disability associated with cardiovascular and other disease.

\section{FOLLOW UP}

Fatal cardiovascular disease events were ascertained through the National Health Service (NHS) Central Registers in Southport and Edinburgh. Non-fatal cardiovascular events (myocardial infarction and angina) were notified by general practitioners (GPs) using a standard card as and when they occurred. In addition, biennial reviews of patients' notes were carried out to find events that the doctor had failed to notify at the time.${ }^{14}$ In the $1986-8$ review, this inquiry was extended retrospectively to ascertain whether and when coronary artery bypass surgery had taken place in the past eight years, and since then it has been routinely determined in each biennial review. Reports of coronary artery bypass surgery by the men in the 1992 questionnaire (see below) were compared with GP records, and discrepancies noted. General practices reviewed again the records of men for whom discrepancies existed.

\section{SMOKING STATUS}

Men were defined as "never-smokers", "exsmokers", or "current smokers" according to their self-reported cigarette smoking status at Q1. ${ }^{15}$ Data from Q1 were combined with reported smoking status at $\mathrm{Q} 5$, so that those who stopped smoking between Q1 and Q5 could be compared with those who continued to smoke.

The validity of questionnaire smoking status was supported by its strong relation to levels of blood cadmium, which is considered a strong biological marker of smoking. ${ }^{16}$ Smoking status in this study has also been shown to be strongly associated with many physiological variables known to be influenced by smoking such as lung function, haematocrit, and heart rate.

USE OF CARDIOLOGICAL SERVICES

One section of Q92 contained the question "Have you had any of the following?", followed by a list which included "referral to a heart specialist", " $x$-ray or angiogram of your coronary arteries", "angioplasty of coronary arteries", and "coronary artery bypass graft". Thus, reported usage of cardiological services was compared between surviving groups of men defined by their smoking status at screening.

\section{ISCHAEMIC HEART DISEASE}

Differences between subgroups (according to age, region, social class, and smoking) in incidence of major ischaemic heart disease events (comprising fatal ischaemic heart disease, including sudden cardiac death, and non-fatal myocardial infarction ${ }^{15}$ ) were compared with differences in coronary artery bypass surgery incidence. In multifactorial analysis of the probability of coronary artery bypass surgery, however, new episodes of myocardial infarction (major event) and angina (non-major event) were used as separate covariates, representing measures of clinical need.

\section{STATISTICAL ANALYSIS}

The primary endpoint was coronary artery bypass surgery reported by a general practitioner before the end of December 1991. Cox's proportional hazards survival analysis ${ }^{17}$ was applied: the relative likelihood of surgery in subgroups of men was estimated using the hazard ratio, similar in concept to an odds ratio. Some of the factors were fixed at the beginning of the study - for example, whether either parent had already died from heart trouble, but others (time dependent covariates) varied over the course of follow up. These included incidence of a new episode of angina or myocardial infarction. It was necessary to take into account new episodes, because these were related to the probability of surgery independently of pre-existing levels of ischaemic heart disease. Those who died before the end of 1991 without having received a coronary artery bypass graft were regarded as "censored" observations: they were regarded as at risk of coronary artery bypass surgery until that point. If the day or month of coronary artery bypass surgery was not known, it was set to 15 or 6 respectively. If any subject underwent two coronary artery bypass operations during the study, only the first was considered for analysis.

\section{DEFINITIONS OF VARIABLES INCLUDED IN} SURVIVAL ANALYSIS

Apart from smoking status and incidence of myocardial infarction and angina, other variables were regarded as fixed from the start of the study. Social class was defined by the Registrar General's Classification of Occupations according to the longest held occupation at Q1. Region of residence was regarded as north or south depending on whether the town of residence at Q1 lay north or south of the line joining Bristol and The Wash; this simplified a previous classification. ${ }^{18}$ The distribution of serum cholesterol was divided into fifths, as was diastolic blood pressure, which was chosen rather than systolic because it showed a stronger association with coronary artery bypass surgery in unifactor 
Table 1 Incidence of fatal or major non-fatal episodes of ischaemic heart disease (IHD) and coronary artery bypass surgery between screening (Q1) and 31 December 1991

\begin{tabular}{|c|c|c|c|c|c|}
\hline \multirow[b]{2}{*}{ Subgroups } & \multirow[b]{2}{*}{$\begin{array}{l}\text { Number of } \\
\text { men at risk }\end{array}$} & \multicolumn{2}{|c|}{ Fatal or non-fatal IHD } & \multicolumn{2}{|c|}{ Coronary artery bypass surgery } \\
\hline & & $\begin{array}{l}\text { Number } \\
\text { (rate/1000/year) }\end{array}$ & $\begin{array}{l}\text { Hazard ratio ( } 95 \% \\
\text { confidence interval) }\end{array}$ & $\begin{array}{l}\text { Number } \\
\text { (rate/1000/year) }\end{array}$ & $\begin{array}{l}\text { Hazard ratio }(95 \% \\
\text { confidence interval) }\end{array}$ \\
\hline \multicolumn{6}{|l|}{ Social class: } \\
\hline Non-manual & 3059 & $283(7 \cdot 56)$ & $1 \cdot 00$ & $45(1 \cdot 21)$ & $1 \cdot 00$ \\
\hline Manual & 4428 & $512(9 \cdot 82)$ & $1.29(1.11$ to 1.49$)$ & $56(1.08)$ & $0.91(0.62$ to 1.35$)$ \\
\hline \multicolumn{6}{|l|}{ Region of residence: } \\
\hline North & 5766 & $669(9 \cdot 70)$ & $1 \cdot 00$ & $83(1 \cdot 22)$ & 1.00 \\
\hline South & 1967 & $155(6 \cdot 42)$ & $0.66(0.56$ to 0.79$)$ & $21(0.88)$ & $0.72(0.45$ to 1.17$)$ \\
\hline \multicolumn{6}{|l|}{ Age group at $Q 1$ : } \\
\hline $40-44$ & 1838 & $92(4 \cdot 00)$ & 1.00 & $21(0.91)$ & 1.00 \\
\hline $45-49$ & 1898 & $168(7 \cdot 29)$ & $1.83(1.42$ to 2.35$)$ & $27(1 \cdot 17)$ & $1.28(0.73$ to 2.27$)$ \\
\hline $50-54$ & 1973 & $247(10.5)$ & $2.62(2.06$ to 3.33$)$ & $36(1.54)$ & $1.71(1.00$ to 2.94$)$ \\
\hline $55-59$ & 2024 & $317(13 \cdot 5)$ & $3 \cdot 38(2 \cdot 68$ to $4 \cdot 26)$ & $20(0 \cdot 88)$ & $1.00(0.54$ to 1.84$)$ \\
\hline \multicolumn{6}{|l|}{ Smoking status at $\mathrm{Q} 1$ : } \\
\hline Current smokers & 3185 & $432(11 \cdot 5)$ & 1.00 & $38(1.03)$ & $1 \cdot 00$ \\
\hline Ex-smokers & 2715 & $286(8.74)$ & $0.76(0.66$ to 0.88$)$ & $47(1 \cdot 45)$ & $1.39(0.90$ to 2.13$)$ \\
\hline Never smokers & 1817 & $105(4 \cdot 65)$ & $0.40(0.32$ to 0.50$)$ & $19(0 \cdot 85)$ & $0.80(0.46$ to 1.39$)$ \\
\hline
\end{tabular}

analysis. (This choice did not affect the observed relation between smoking and coronary artery bypass surgery.) Parental death from heart trouble was a dichotomous variable, including death of mother, father, or both as a potential risk group. Following previous criteria, pre-existing ischaemic heart disease (IHD) was defined in three groups as no evidence, possible evidence of IHD, and definite evidence of myocardial infarction, ${ }^{19}$ while breathlessness was categorised as none, mild, moderate or severe. ${ }^{20}$

\section{Results}

Altogether coronary artery bypass grafts were confirmed from GP records in 104 men. Nine took place between 1978 and 1982, 41 between 1983 and 1986, and the remaining 54 between 1987 and 1991. Two men had undergone coronary artery bypass surgery before the start of the study and were excluded from analysis.

\section{FACTORS AFFECTING CORONARY ARTERY} BYPASS SURGERY RATES

Table 1 shows the incidence of major ischaemic heart disease and the incidence of coronary artery bypass surgery. Although manual workers had higher disease incidence, they had lower coronary artery bypass surgery

Table 2 Hazard ratios for coronary artery bypass surgery according to various risk groups, adjusted for other factors

\begin{tabular}{|c|c|c|}
\hline Subgroups & $\begin{array}{l}\text { Hazard ratio ( } 95 \% \\
\text { confidence interval), } \\
\text { adjusted for incidence of } \\
\text { MI and angina in follow up }\end{array}$ & $\begin{array}{l}\text { Hazard ratio ( } 95 \% \\
\text { confidence interval), } \\
\text { adjusted for all variables * }\end{array}$ \\
\hline $\begin{array}{l}\text { Social class: } \\
\text { Non-manual } \\
\text { Manual }\end{array}$ & $\begin{array}{l}1.00 \\
0.86(0.58 \text { to } 1.27)\end{array}$ & $\begin{array}{l}1.00 \\
0.91(0.59 \text { to } 1.40)\end{array}$ \\
\hline $\begin{array}{l}\text { Region of residence } \\
\text { North } \\
\text { South }\end{array}$ & $\begin{array}{l}1.00 \\
0.81(0.50 \text { to } 1.31)\end{array}$ & $\begin{array}{l}1.00 \\
0.91(0.54 \text { to } 1.52)\end{array}$ \\
\hline $\begin{array}{l}\text { Age group: } \\
40-44 \\
45-49 \\
50-54 \\
55-59\end{array}$ & $\begin{array}{l}1.00 \\
0.99(0.56 \text { to } 1.75) \\
1.20(0.70 \text { to } 2.07) \\
0.67(0.36 \text { to } 1.24)\end{array}$ & $\begin{array}{l}1.00 \\
0.88(0.48 \text { to } 1.60) \\
1.00(0.56 \text { to } 1.78) \\
0.51(0.26 \text { to } 0.98)\end{array}$ \\
\hline $\begin{array}{l}\text { Smoking status: } \\
\text { Current smoker } \\
\text { Ex-smoker } \\
\text { Never smoker }\end{array}$ & $\begin{array}{l}1.00 \\
1.52(0.99 \text { to } 2.34) \\
1.00(0.57 \text { to } 1.73)\end{array}$ & $\begin{array}{l}1.00 \\
1.34(0.84 \text { to } 2 \cdot 12) \\
0.99(0.55 \text { to } 1.79)\end{array}$ \\
\hline
\end{tabular}

*Each hazard ratio is adjusted both for the other variables listed in the table and also parental death from heart trouble, pre-existence of ischaemic heart disease, myocardial infarction and angina during follow up, serum cholesterol, diastolic blood pressure, and breathlessness. rates. Both coronary artery bypass surgery and ischaemic heart disease were more common in those living in the north. Although incidence of ischaemic heart disease increased steadily with age at screening, coronary artery bypass surgery rates increased only slightly over the three age groups from 40 to 54 years, and were lowest for those aged 55 to 59 years at screening. Current smokers (as defined at Q1) were more likely to experience major ischaemic heart disease events than either ex-smokers or never-smokers, but ex-smokers were the group most likely to undergo coronary artery bypass surgery.

Clinical characteristics known to be risk factors for ischaemic heart disease were related to the likelihood of receiving coronary artery bypass surgery (data not shown). Particularly strong associations were found with preexisting ischaemic heart disease, incidence of myocardial infarction or angina during follow up, moderate breathlessness, and high serum cholesterol $(>7 \cdot 2 \mathrm{mmol} / \mathrm{l})$. Moderate associations were found with parental death from heart trouble, diastolic blood pressure in the top fifth of the distribution, and severe breathlessness.

SURVIVAL ANALYSIS OF CORONARY ARTERY BYPASS SURGERY

The relation between coronary artery bypass surgery during the follow up period and the variables listed in table 1 was investigated with Cox's proportional hazards model. Hazard ratios are shown in table 2 for these variables, firstly adjusted only for clinical need represented by events of angina and myocardial infarction in follow up, and secondly adjusted in a model including all variables, both those listed in table 1 and all the clinical variables listed above. No significant relation was demonstrated between region of residence or social class and coronary artery bypass surgery. When adjustments for all variables were made, men aged 55 to 59 years at screening were about half as likely to undergo coronary artery bypass surgery as those aged 40 to $44(\mathrm{P}=0.08$ for comparison of the four age groups). Ex-smokers were 52 per cent more likely to undergo coronary artery bypass surgery than current smokers when adjustment was made only for incidence of myocar- 
Table 3 Smoking status of men at $Q 1$ (screening) in relation to coexistent evidence of ischaemic heart disease

\begin{tabular}{lccr}
\hline Evidence & Current smokers & Ex-smokers & Never smokers \\
\hline ECG evidence of ischaemia: & & & \\
$\quad$ None & $2697(84 \cdot 7)$ & $2304(84 \cdot 9)$ & $1586(87 \cdot 5)$ \\
Myocardial ischaemia or & $373(11 \cdot 8)$ & $317(11 \cdot 6)$ & $191(10 \cdot 5)$ \\
$\quad$ possible infarct & $113(3 \cdot 6)$ & $92(3 \cdot 4)$ & $36(2 \cdot 0)$ \\
Definite MI & $3183(100)$ & $2713(100)$ & $1813(100)$ \\
Total (\%) & & & \\
$\begin{array}{l}\text { WHO questionnaire on } \\
\text { chest pain: }\end{array}$ & $2678(84 \cdot 2)$ & $2306(85 \cdot 2)$ & $1627(89 \cdot 5)$ \\
$\quad$ None & $181(5 \cdot 7)$ & $136(5 \cdot 0)$ & $74(4 \cdot 1)$ \\
Angina & $320(10 \cdot 1)$ & $266(9 \cdot 8)$ & $114(6 \cdot 4)$ \\
Myocardial infarction & $3179(100)$ & $2708(100)$ & $1815(100)$ \\
Total (\%) & & & \\
Recall of doctor diagnosis: & $3009(94 \cdot 7)$ & $2520(92 \cdot 9)$ & $1759(96 \cdot 9)$ \\
$\quad$ None & $47(1 \cdot 5)$ & $58(2 \cdot 1)$ & $26(1 \cdot 4)$ \\
Angina & $123(3 \cdot 8)$ & $134(5 \cdot 0)$ & $31(1 \cdot 7)$ \\
Myocardial infarction & $3179(100)$ & $2712(100)$ & $1816(100)$ \\
Total (\%) & &
\end{tabular}

dial infarction or angina during follow up $(P=0.055)$. This excess was reduced to 43 per cent after adjustments for all additional variables except breathlessness $(P=0 \cdot 12)$ and to 34 per cent $(P=0 \cdot 21)$ when breathlessness was included.

Some of the other variables included in the multifactorial analysis continued to be strongly and independently associated with coronary artery bypass surgery, namely pre-existing ischaemic heart disease, incidence of angina or myocardial infarction during follow up, incidence of angina, and serum cholesterol $>7 \cdot 2$ $\mathrm{mmol} / \mathrm{l}$.

\section{CHANGES IN SMOKING HABITS DURING FOLLOW-UP AND CORONARY ARTERY BYPASS SURGERY}

After the fifth year questionnaire (Q5), 83 men underwent coronary artery bypass surgery. Among the men who had become exsmokers between Q1 and Q5, the subsequent coronary artery bypass surgery rate was $2 \cdot 30 / 1000 /$ year, while for those who had continued smoking it was $1 \cdot 17 / 1000$ /year (hazard ratio $1.98,95 \%$ confidence interval 0.95 to $4 \cdot 11, \mathrm{P}=0.067$ ), and it was $1 \cdot 84 / 1000 /$ year for those who had been ex-smokers throughout the study.

SMOKING STATUS AND COEXISTING ISCHAEMIC HEART DISEASE

Because coronary artery bypass surgery was more frequent in ex-smokers than current smokers, detailed analysis was carried out to compare ex-smokers and current smokers for severity of ischaemic heart disease at screening according to three criteria: the electrocardiogram, the WHO (Rose) chest pain questionnaire, and patient recall of a doctor diagnosis. Table 3 shows that according to the first two criteria, evidence of myocardial infarction and angina was less frequent in ex-smokers than current smokers. However, ex-smokers were more likely to report previous doctor diagnoses of possible myocardial infarction or angina.

A similar analysis was carried out on information available after five years (Q5). Myocardial infarction according to the WHO (Rose) questionnaire was more frequent in new ex-smokers $(9 \cdot 3 \%)$ than continuing smokers (5.9\%). Recall of a doctor diagnosis of myocardial infarction was more frequent in new ex-smokers $(12.5 \%)$ than continuing smokers $(4 \cdot 4 \%)$.

Among those with recall of a doctor diagnosis of ischaemic heart disease at screening, six (3.5\%) of 170 current smokers subsequently underwent coronary artery bypass surgery, compared with 18 of 192 ex-smokers $(9 \cdot 4 \%)$ $(P=0.026)$. Among those reporting this diagnosis at $\mathrm{Q} 5$, subsequent frequency of coronary artery bypass surgery was seven $(4.5 \%)$ of 155 continuing smokers, eight $(6.8 \%)$ of 118 continuing ex-smokers, and 21 $(9 \cdot 4 \%)$ of 224 new ex-smokers ( $P=0.2$ for comparison of three groups). Thus even though recall of a doctor diagnosis of ischaemic heart disease was more common in ex-smokers than current smokers, current smokers who recalled the diagnosis were less likely to undergo coronary artery bypass surgery than ex-smokers who recalled the diagnosis. Therefore the distribution of ischaemic heart disease at screening was not the explanation for higher rates of surgery in ex-smokers.

USE OF CARDIOLOGICAL SERVICES

For men defined by smoking status at Q1 who survived until 1992 and answered appropriate items on Q92, $374(18.5 \%)$ of 2027 smokers were referred to a heart specialist, compared with $388(18.8 \%)$ of 2069 ex-smokers ( $P=$ $0 \cdot 8$ ). Reports of angiography were made by $249(12 \cdot 7 \%)$ of 1964 smokers and 232 $(11 \cdot 5 \%)$ of 2022 ex-smokers $(P=0 \cdot 24)$.

\section{Discussion}

This prospective study suggests that men who continued to smoke were less likely to undergo coronary artery bypass surgery than men who had given up smoking. This is despite the higher incidence of ischaemic heart disease in smokers than ex-smokers. After adjusting for incidence of angina or myocardial infarction during follow up, ex-smokers were about 50 per cent more likely to undergo coronary artery bypass surgery than smokers. The excess risk still applied, albeit to a lesser and non-significant extent, when adjustments were made for other clinical variables. Ex-smokers were in fact more likely than continuing smokers to recall a doctor diagnosis of ischaemic heart disease, despite the fact that objective evidence from electrocardiography indicated more disease in the smoking group. However, when analysis was restricted to men who recalled a doctor diagnosis of ischaemic heart disease, smokers were still less likely to undergo coronary artery bypass surgery than ex-smokers. Among those surviving until 1992, smokers were no less likely than exsmokers to report having been referred to a heart specialist or to have undergone angiography.

Our study has also shown that for those aged 55 to 59 at screening, and thus in their late $60 \mathrm{~s}$ around the median date of coronary artery bypass surgery seen in the study, the 
coronary artery bypass surgery rate scarcely differed from those aged 40 to 44 at screening, despite the higher incidence of major ischaemic heart disease in the older age group. Our study has been unable to substantiate any association between social class and coronary artery bypass surgery as being statistically significant; nevertheless men with a manual occupation had lower rates of coronary artery bypass surgery despite their higher incidence of major ischaemic heart disease. Finally, we have not been able to show any difference in coronary artery bypass surgery rates between the north and south of Britain.

The number of coronary artery bypass grafts in our study was small, and this probably explains why the statistical significance of the findings was not strong. Further follow up in our study will increase the number of coronary artery bypass grafts, but the dynamics of selection for surgery may well alter in the next few years. It was important to describe the current situation, in view of recent work on the influence of non-clinical factors on revascularisation rates. ${ }^{3-6}$ Despite the small numbers, different analyses with regard to smoking status reported in this paper were consistent in their results. In particular, analysis of the whole follow up period and for the period following the fifth year questionnaire, were consistent. Thus the loss through death early in the study of men who would have been candidates for coronary artery bypass surgery does not account for our findings.

The biennial record review was extended to recording coronary artery bypass surgery in 1988, some eight years into the follow up period. Efforts were made to check the entire history of coronary artery bypass surgery for surviving men from screening onwards, and additionally cross validation was applied using men's reports in Q92. However, coronary artery bypass grafts carried out in men who died early in the study would have been missed by our method. The observed rate of coronary artery bypass surgery in our sample was lower in the earlier years of the study, but this could be explained by the slow diffusion of the technology into clinical practice; Department of Health recommendations for national targets were not made until $1987 .{ }^{21}$

Several studies have reported a relation between coronary artery bypass surgery rates and demographic variables such as gender, ${ }^{3}$ social deprivation, ${ }^{45}$ ethnicity, ${ }^{8}$ and age group, ${ }^{22}$ using aggregated data for electoral wards or other geographically defined areas. Findings from four British regions between 1987 and 1992 showed that coronary artery bypass surgery and coronary angioplasty occurred most frequently in those aged 55 to 64 , less frequently in those aged 65 to 74 , and rarely in those aged 75 or more. ${ }^{22}$ Our data are consistent with this finding, showing that those aged 55-59 at screening and thus likely to be in their late 60 s around the median date of coronary artery bypass surgery for this study, were half as likely to undergo coronary artery bypass surgery than those who were around 15 years younger.
In Glasgow, low angiography rates were shown to be related to social deprivation, ${ }^{4}$ while in the North East Thames Region, men in moderately deprived electoral wards had lower rates of coronary artery bypass surgery than other men. ${ }^{5}$ Although our data cannot confirm lower coronary artery bypass surgery rates among men in manual social classes, smoking may play a limited part in the social deprivation effect described in these studies.

Considerable debate over the ethics of not offering coronary artery bypass surgery to smokers has taken place in recent years. ${ }^{9-11}$ Coronary artery bypass surgery is considered to convey fewer benefits and pose greater risks in smokers. ${ }^{23}$ The stated policy in one cardiac surgery unit where coronary artery bypass graft is not offered to smokers is to provide anti-smoking advice. Such a policy suggests that patients who stop smoking may then become eligible for coronary artery bypass surgery, and higher coronary artery bypass surgery rates in ex-smokers than continuing smokers would thus be expected. However, evidence from the European Coronary Surgery Study showed that the relative benefit of coronary artery bypass surgery compared with medical treatment was as great for current smokers as for other subjects. ${ }^{24}$ In this case, absolute benefits will be greater for smokers as a higher risk group, and the number needed to treat to prevent a major vascular event will be fewer. ${ }^{25}$

One variable which seemed to explain in part the lower coronary artery bypass surgery rate for smokers was breathlessness, which may have been considered a contraindication for major surgery. ${ }^{26}$ Our study does not include detailed measures of clinical indications for surgery such as left ventricular dysfunction. However, none of the measures of ischaemic heart disease, whether based on electrocardiographic findings or reports on questionnaire, have explained why ex-smokers were more likely to undergo surgery.

To study the incidence of coronary artery bypass surgery among smoking groups, we have used measures of smoking status made at the start of the study and after five years of follow up, whereas coronary artery bypass surgery could occur at any time during 11.5 years of follow up. These measures may be somewhat removed from the point at which cardiac surgeons would consider intervention. Hence men defined as smokers on our questionnaire may have given up smoking in the months before surgery. If so, our analysis would have underestimated the greater likelihood of surgery for ex-smokers.

It may also be argued that men discounted for coronary artery bypass surgery despite appropriate clinical indications would instead be offered angioplasty, but record reviews identified very few before 1992. This study's follow up period ended in 1991 and usage of angioplasty was probably lower than that of coronary artery bypass surgery. However, cardiologists may increasingly be choosing angioplasty as an alternative to coronary artery bypass surgery for smokers. 
Our data leave open three compatible possibilities. First, coronary artery bypass surgery was less likely to be offered to smokers because of their supposed reduced ability to benefit. Second, some smokers who were placed on a lengthy waiting list for coronary artery bypass surgery, may have become ex-smokers while they waited because of their frightening experience of ischaemic heart disease. Waiting times can be protracted: for NHS patients in a district in the South West Thames Region in 1988 , the mean wait from referral to angiography was 116 days, while mean wait from angiography until either coronary artery bypass surgery or angioplasty was 306 days. $^{6}$ Third, cardiologists or cardiac surgeons may have used the withholding of surgery as a bargaining tool to induce smokers to quit. ${ }^{23}$ Our data suggest that if a bias was operating against smokers being offered coronary artery bypass surgery, it was happening after angiography was carried out. We believe that detailed follow up studies of patients with different smoking histories presenting with angina to primary, secondary, and tertiary care, would help to elucidate this.

In conclusion, this prospective observational study of middle aged men drawn from general practices all over Britain has shown that continuing smokers were less likely to undergo coronary artery bypass surgery than ex-smokers, even after allowing for the strong relation between criteria for clinical need and coronary artery bypass surgery. There is a complex interplay between the men's experience of ischaemic heart disease, their decision to stop smoking and the willingness of doctors to consider coronary artery bypass surgery.

The British Regional Heart Study is funded by the British Heart Foundation with additional support from the Department of Health and the Stroke Association.

1 Secretary of State for Health. The health of the nation.

2 Yusuf S, Zucker D, Peduzzi P, Fisher LD, Takaro T, usuf S, Zucker D, Peduzzi P, Fisher LD, Takaro T,
Kennedy JW, et al. Effect of coronary artery bypass graft surgery on survival: overview of 10-year results from randomised trials by the Coronary Artery Bypass Graft Surgery Trialists Collaboration. Lancet 1994;344: 563-70.
3 Kee F, Gaffney B, Currie S, O'Reilly D. Access to coronary catheterisation: fair shares for all? $B M \mathcal{F}$ 1993;307 1305-7.

4 Findlay IN, Dargie HJ, Dyke T. Coronary angiography in Glasgow: relation to coronary heart disease and social class. Br Heart f 1991;66:70

5 Ben Shlomo Y, Chaturvedi N. Assessing equity in access to health care provision in the UK: does where you live affect your chances of getting a coronary artery bypass graft? $\mathcal{F}$ Epidemiol Community Health 1995;49:200-4.

6 Marber M, MacRae C, Joy M. Delay to invasive investigation and revascularisation for coronary heart disease in South West Thames region: a two tier system. BMF 1991;302:1189-91.

7 Whittle J, Conigliaro J, Good CB, Lofgren RP. Racial differences in the use of invasive cardiological procedures in the department of Veterans Affairs Medical System. $N$ Engl F Med 1993;329:621-7.

8 Goldberg KC, Hartz AJ, Jacobsen SJ, Krakauer H, Rimm AA. Racial and community factors influencing coronary artery bypass surgery rates for all 1986 Medicare patients. $\mathscr{F} A M A$ 1992;267:1473-7.

9 Grimes DS. Should patients who smoke be referred for coronary artery bypass grafting? Lancet 1988;i:1157.

10 Underwood MJ, Bailey JS, Shiu M, Higgs R, Garfield J. Should smokers be offered coronary bypass surgery? Should smokers be offe

11 Powell JT, Greenhalgh RM. Arterial bypass surgery and smokers. BMF 1994;308:607-8.

12 Central Statistical Office. Social Trends 23. 1993 edition. London: HMSO, 1993: 103.

13 Shaper AG, Pocock SJ, Walker M, Cohen NM, Wale CJ, Thomson AG. British Regional Heart Study: cardiovascular risk factors in middle-aged men in 24 towns. BMF 1981;283:179-86.

14 Walker M, Shaper AG. Follow-up of subjects in prospective studies based in general practice. F $R$ Coll Gen Pract 1984;34:365-70.

15 Shaper AG, Pocock SJ, Walker M, Phillips AN, Whitehead TP, MacFarlane PW. Risk factors for ischaemic hear disease: the prospective phase of the British Regional Heart Study. $\mathcal{F}$ Epidemiol Community Health 1985;39: 197-209.

16 Pocock SJ, Delves HT, Ashby D, Shaper AG, Clayton BE. Blood cadmium concentrations in the general population of British middle-aged men. Human Toxicol 1988;7 95-103.

17 Cox DR. Regression models for life tables (with discussion). $\mathcal{F} R$ Statist Soc (B) 1972;34:187-220.

18 Elford J, Phillips AN, Thomson AG, Shaper AG. Migration and geographic variations in ischaemic heart disease in Great Britain. Lancet 1989;i:343-6.

19 Phillips AN, Shaper AG, Pocock SJ, Walker M MacFarlane PW. The role of risk factors in heart attacks occurring in men with pre-existing ischaemic heart disoccurring in men with pre-existing

20 Cook DG, Shaper AG. Breathlessness, lung function and the risk of heart attack. Eur Heart $₹$ 1988;9:1215-22.

21 Department of Health and Social Security. Health Services development: resource assumptions and planning guidedines. HC(87)7. London: DHSS, 1987.

22 Black N, Langham S, Petticrew M. Trends in the age and sex of patients undergoing coronary revascularisation in sex of patients undergoing coronary revascularisation in the Unit-20.

23 Mogielnicki RP, Bell J, Fowler FJ. The influence of patient smoking status on therapeutic decisions. $\mathcal{J}$ Gen Intern smoking status on
Med 1992;7:165-9.

24 Julian DG. Smoking and coronary artery bypass surgery. $\mathrm{Br}$ Heart f 1994;72:9-11.

25 Davey Smith G, Egger M. Who benefits from medical interventions? $B M F$ 1994;308:72-4.

26 Freeman JM, Clutton-Brock TH. Adult cardiac anaesthesia. Br $\mathcal{F}$ Hosp Med 1994;51:40-3. 